\title{
Investigation of the effect of residual stresses in the subsurface on process forces for consecutive orthogonal cuts
}

\author{
F. Wöste' ${ }^{1}$ J. Kimm² J. A. Bergmann ${ }^{1} \cdot$ W. Theisen ${ }^{2} \cdot$ P. Wiederkehr ${ }^{1}$
}

Received: 15 March 2021 / Accepted: 3 May 2021 / Published online: 22 May 2021

(c) The Author(s) 2021

\begin{abstract}
The quality and surface integrity of machined parts is influenced by residual stresses in the subsurface resulting from cutting operations. These stress characteristics can not only affect functional properties such as fatigue life, but also the process forces during machining. Especially for orthogonal cutting as an appropriate experimental analogy setup for machining operations like milling, different undeformed chip thicknesses cause specific residual stress formations in the subsurface area. In this work, the process-related depth profile of the residual stress in AISI 4140 was investigated and correlated to the resulting cutting forces. Furthermore, an analysis of the microstructure of the cut material was performed, using additional characterization techniques such as electron backscatter diffraction and nanoindentation to account for subsurface alterations. On this basis, the influence of process-related stress profiles on the process forces for consecutive orthogonal cutting strategies is evaluated and compared to the results of a numerical model. The insights obtained provide a basis for future investigations on, e. g., empirical modeling of process forces including the influence of process-specific characteristics such as residual stress.
\end{abstract}

Keywords Machining $\cdot$ Surface integrity $\cdot$ Residual stress $\cdot$ Process forces $\cdot$ Finite element method (FEM)

\section{Introduction}

Process forces occurring in machining operations such as milling are decisive for, e.g., the progress of tool wear [1] or the occurrence of dynamic effects like regenerative chatter [2]. A precise calculation of the process forces is necessary in order to predict these effects as a means of improving machining operations $[1,3]$. For this purpose, empirical models can be used by considering the material removal process based on a geometric analysis of the tool engagement $[4,5]$. By applying, e. g., geometric physically-based simulation systems, an efficient evaluation of complex machining strategies with respect to forces and occuring deflections is possible [3]. The chip formation process is not considered on a local scale within the process model of theses simulation systems. Suitable means for a detailed analysis of the chip formation are for instance analytical models [6]

\section{F. Wöste}

florian.woeste@tu-dortmund.de

1 Virtual Machining, TU Dortmund University, Otto-Hahn-Str. 12, 44227 Dortmund, Germany

2 Chair of Materials Technology, Ruhr University Bochum, 44780 Bochum, Germany or constitutive material models using a finite element $(\mathrm{FE})$ simulation $[7,8]$.

A characteristic of these empirical models is the assumption of a homogeneous behavior of the workpiece material. Therefore, the influence of subsurface alterations generated by preceding cuts on the process forces is not considered explicitly in such models. However, process-related changes of subsurface characteristics can have a significant effect on subsequent cuts and the corresponding process forces [9]. To account for this effect of material history, an approach was presented to improve the evaluation of cutting forces using an extended process model of a geometric physically-based simulation system [9]. The influence of specific subsurface alterations on the resulting process forces, in particular the formation of residual stress as an important characteristic $[10,11]$, was not considered in this context. Previous studies have focused, for instance, on the stress formation resulting from consecutive cutting strategies [12,13], rather than on its contribution to the cutting forces of the respective cuts. To address this knowledge gap, cutting experiments were conducted within the scope of this study to indentify the effect of residual stress characteristics on process forces. Hereby, the resulting depth profile of the residual stress formation was analyzed for different undeformed chip thicknesses, 
which have a significant influence particularly on the compressive stress profile [14]. For a fundamental investigations, orthogonal cutting experiments were conducted as a suitable analogy setup. Scanning electron microscopy (SEM) and electron backscatter diffraction (EBSD) measurements of the cut workpiece material were performed as well as nanoindentation tests to provide a more extensive characterization of the subsurface, which is relevant for the correlation of residual stresses and cutting forces. The resulting insights provide a basis for future investigations on empirical modeling of process forces taking into account the influence of residual stress. In this regard, the use of numerical simulations is an effective tool to augment the experimental data set and to consider different process scenarios. Consequently, a numerical model was set up and compared to the experimental results in order to evaluate its basic ability to simulate the identified effect of material history.

\section{Experimental procedure}

In order to analyze the influence of process-related residual stress, cutting experiments consisting of sequences of consecutive orthogonal cuts were conducted (Sect. 2.1). For this purpose, a modular cutting system was used to ensure a high reproducibility of the experiments without a significant influence of disturbing dynamic effects [15]. The depth profiles of the residual stress were measured for machined workpiece samples by using electrolytic etching to remove a defined material layer and X-ray diffraction to detect the stress state. The use of SEM and EBSD measurements and nanoindentation tests as additional characterization techniques provided information on process-related changes in the microstructure of the workpiece (Sect. 2.2).

\subsection{Preparation and conduction of cutting experiments}

The consecutive cutting strategy conducted in the experiments is illustrated in Fig. 1a. The initial cut was carried out with an undeformed chip thickness of $h=150 \mu \mathrm{m}$ and $210 \mu \mathrm{m}$, respectively, which correspond to applicable thicknesses with regard to roughing processes in milling. In analogy to finishing processes, cuts with a smaller thickness of $h=70 \mu \mathrm{m}$ were conducted subsequently. The experimental setup is presented in Fig. 1 b.

The cutting element used as a tool was manufactured from the high-speed steel (HSS) AISI M2 and heat treated in a vacuum furnace. The tool blank was quenched from $1220^{\circ} \mathrm{C}$ with nitrogen gas at a pressure of 3 bar and consequently tempered three times at $560^{\circ} \mathrm{C}$ in a nitrogen gas atmosphere. As a result, a completely martensitic microstructure with a secondary maximum hardness of $860 \mathrm{HV} 30$ was formed. After grinding the initial shape, the cutting edge micro shape was prepared by wet abrasive jet machining resulting in a form factor of $K=1$ and a radius of $r_{\beta}=20 \mu \mathrm{m}$. The workpiece samples were made from AISI 4140 flat steel, which was austenitized in an inert gas atmosphere at $850^{\circ} \mathrm{C}$ and hardened in water. Subsequently the samples were tempered at $540{ }^{\circ} \mathrm{C}$ for two hours and air-cooled. Through this heat treatment a microstructure of relaxed martensite with a hardness of $380 \mathrm{HV} 30$ was achieved. Afterwards, the samples with a length of $l_{\mathrm{c}}=100 \mathrm{~mm}$ were ground to the final width of $b=3 \mathrm{~mm}$. The process forces occurring during the orthogonal cuts were measured using a dynamometer of the type Kistler 9257B, a charge amplifier of the type Kistler 5070A and the analysis system LDS Dimension 4i. The tool and process parameter values used in the experiments are listed in Table 1.

Table 1 Tool and process parameter values of orthogonal cutting experiments

\begin{tabular}{lll}
\hline Cutting edge radius & $r_{\beta}$ & $20 \mu \mathrm{m}$ \\
Form factor & $K$ & 1 \\
Rake angle & $\gamma$ & $7.5^{\circ}$ \\
Flank angle & $\alpha$ & $5^{\circ}$ \\
Undeformed chip thickness & $h$ & $70,150,210 \mu \mathrm{m}$ \\
Cutting velocity & $v_{\mathrm{c}}$ & $60 \mathrm{~m} \mathrm{~min}^{-1}$ \\
Width of cut & $b$ & $3 \mathrm{~mm}$ \\
Length of cut & $l_{\mathrm{c}}$ & $100 \mathrm{~mm}$ \\
\hline
\end{tabular}

Fig. 1 Illustration of the consecutive orthogonal cutting strategy (a) and the experimental setup (b)
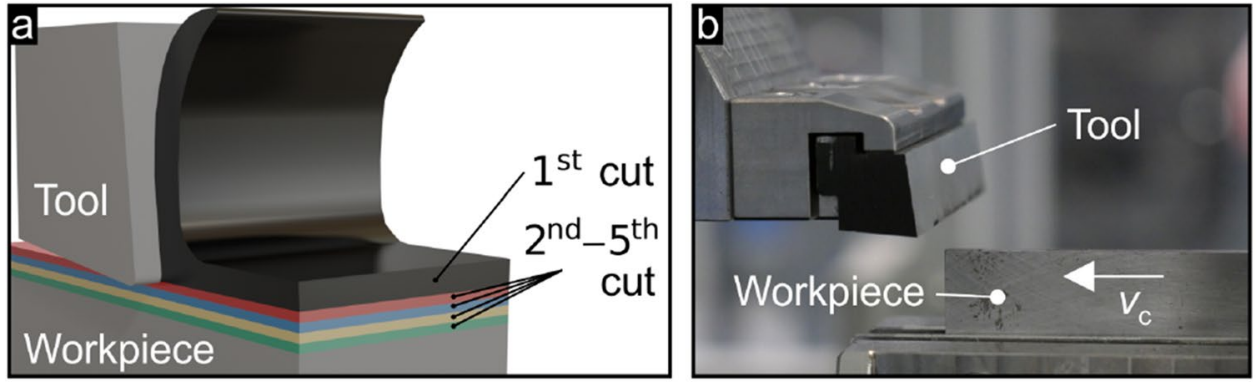


\subsection{Characterization of residual stress}

The residual stress measurements were conducted with a $\mathrm{X}$-ray diffraction detector of the type $\mu$-X360 by Pulstec Industrial Co., Ltd., which uses the single incident angle $\mathrm{X}$-ray exposure method ( $\cos \alpha$-method [16]). CrK $\beta$-radiation was emitted with a tube voltage of $30 \mathrm{kV}$ using a collimator with a diameter of $0.3 \mathrm{~mm}$. The incident angle was $35^{\circ}$ at a working distance of $39 \mathrm{~mm}$. In order to determine the depth profile of the process-related residual stress, a consecutive removal of a defined amount of workpiece material was necessary. Therefore, an electrolytic polishing machine of the type LectroPol- 5 by Struers GmbH with an A2 etchant (70\% ethanol, $12 \%$ distilled water, $10 \%$ 2-butoxyethanol, $8 \%$ perchloric acid) and an etching voltage of $12 \mathrm{~V}$ was used. A linear correlation between the exposure time and the material removal was identified. The exact thickness of the removed material layer was quantified by measurements with a confocal laser scanning microscope (CLSM) of the type VK-X200 by Keyence.

In preparation for the SEM and ESBD measurements, the samples were embedded in epoxy resin, ground and subsequently polished using a vibratory polisher of the type Saphir Vibro by ATM and MasterMet by Buehler as a final polishing suspension to achieve the required surface quality. The optical analysis was performed using a scanning electron microscope of the type Mira 3 by Tescan with the SE contrast and a voltage of $20 \mathrm{kV}$. For EBSD imaging a NordlysNano detector was used.

The nanoindentation tests were conducted with an iMicro Nanoindenter by Nanomechanics, Inc. with a diamond Berkovich indenter [17] and a load of $10 \mathrm{mN}$. The indents were placed in tilted rows, resulting in a distance between the indentation points of $1 \mu \mathrm{m}$ perpendicular to the cut surface of the sample (Fig. 2). The hardness was evaluated using the method of Oliver and Pharr [18].

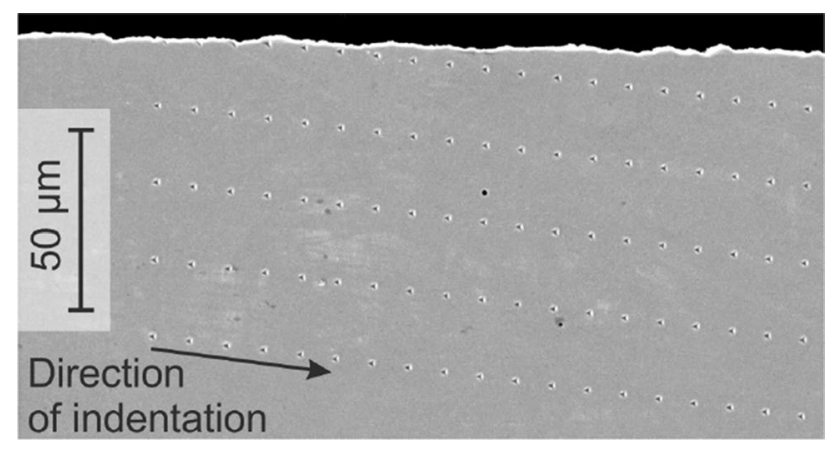

Fig. 2 Positions of the indentation points along the cut surface
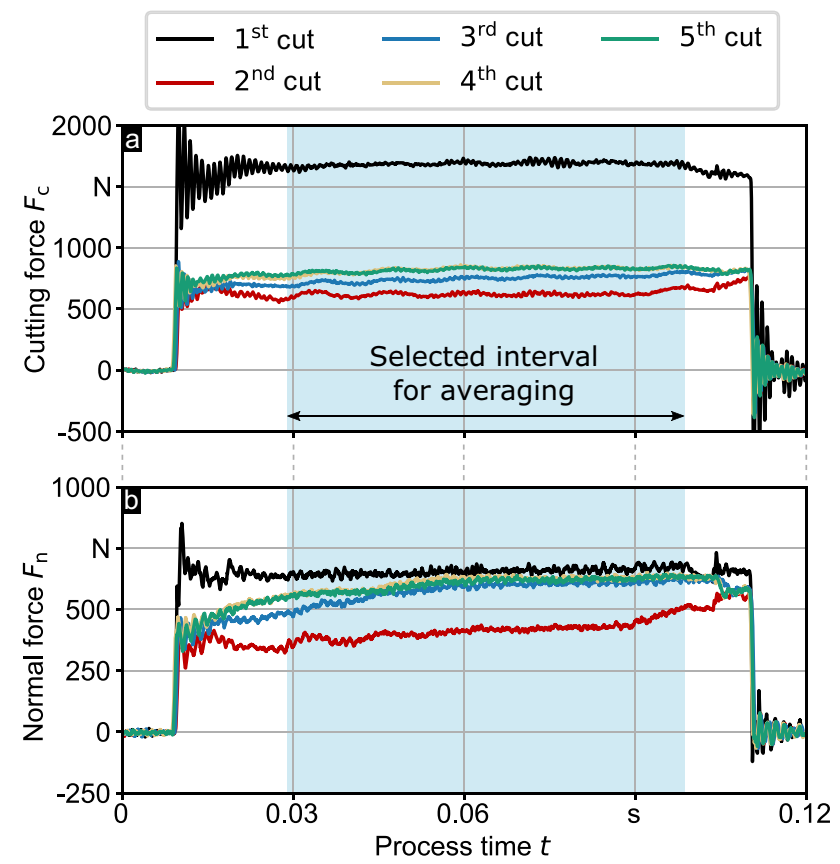

Fig. 3 Process forces in cutting (a) and normal direction (b) for a sequence of consecutive orthogonal cuts. The initial cut was conducted with an undeformed chip thickness of $h=210 \mu \mathrm{m}$, the subsequent cuts with $70 \mu \mathrm{m}$

\section{Experimental results}

The influence of preceding cuts on the process forces of subsequent cuts and a correlation of this effect with regard to the process-related residual stress formation is described in Sects. 3.1 and 3.2. For this purpose, the stress state parallel to the cutting direction $\sigma_{\mathrm{II}}$ was measured and analyzed. An microstructural characterization of the subsurface is provided in Sect. 3.3.

\subsection{Process forces}

The process forces of an exemplary sequence of five consecutive orthogonal cuts are depicted in Fig. 3. The defined cutting velocity led to the formation of continuous chips, which is also indicated by the steady force signal of the measurements. It was observed that the second cut had significantly lower cutting and normal forces than the following cuts, although the defined values of the undeformed chip thickness were the same. After the second cut, the process forces resemble each other closely. In order to verify the systematic characteristic of this effect, several sequences of consecutive cutting experiments were conducted and the averaged force of each cut was determined. For this purpose, an interval was defined which covers a cutting path of $70 \mathrm{~mm}$ length. 

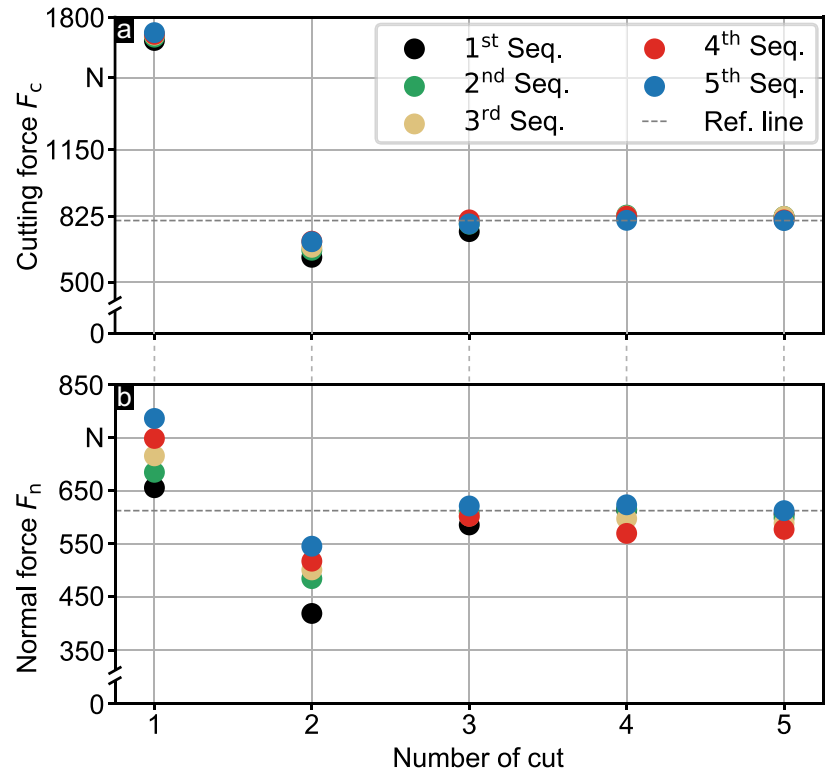

Fig. 4 Average values of the cutting force (a) and the normal force (b) for five sequences of consecutive orthogonal cuts. The initial cut was conducted with an undeformed chip thickness of $h=210 \mu \mathrm{m}$, the subsequent cuts with $70 \mu \mathrm{m}$

The resulting averaged process forces in cutting and normal direction are depicted in Fig. 4 for five cutting sequences, which consisted of five consecutive orthogonal cuts each. The corresponding values of the undeformed chip thicknesses were defined as in the experiments shown in Fig. 3. The cutting and normal forces measured during the second cut were significantly lower compared to the subsequent cuts, in which the forces converged to a constant level. This level is indicated by the grey dotted line, which corresponds to the mean value of the last cut. Additionally, an increase of the process forces particularly

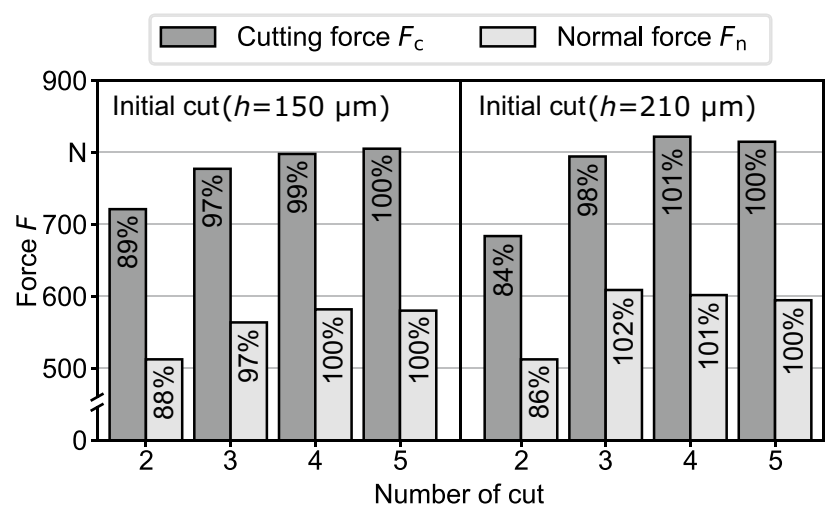

Fig. 5 Averaged process forces of four sequences of consecutive orthogonal cuts. The initial cut was conducted with an undeformed chip thickness of $h=150 \mu \mathrm{m}$ and $210 \mu \mathrm{m}$, respectively. The fifth cut is used as a reference value in normal direction is apparent as the number of conducted cuts increased. This was caused by initial wear progressions of the tool, which occurred during the first engagements of the cutting edge [19]. Nevertheless, a decisive influence of the first cut on the subsequent cut is evident. With regard to the measured process force of the third cut, a systematic influence by the initial cut is not obvious.

In order to quantify the decrease of the process forces after the initial cut and to assess the influence of the undeformed chip thickness on this effect, the averaged cutting and normal forces of four cutting sequences consisting of five orthogonal cuts each were determined, see Fig. 5. To reduce the influence of the initial tool wear progression on the averaged process forces, the first cutting sequence was not included. Since the last cut of a sequence is unlikely to be influenced by the initial cut, the averaged forces of the fifth cut were used as a reference value to quantify the decrease of the forces after the initial cut. In this regard, the cutting and normal forces of the second cut were $11 \%$ and $12 \%$ smaller, following an initial cut with an undeformed chip thickness of $h=150 \mu \mathrm{m}$. This effect amplified with a higher undeformed chip thickness in the initial cut of $h=210 \mu \mathrm{m}$, leading to higher process forces during the initial cut, while the cutting and normal forces decreased by $16 \%$ and $14 \%$ in subsequent cutting operations. After the second cut, the process forces converged to a nearly constant level. An examination of the process-related residual stress as an important characteristic of subsurface alteration and its correlation to the identified effect on process forces is provided in the following.

\subsection{Depth profiles of residual stress}

The depth profiles of residual stress resulting from the first three cuts of a consecutive orthogonal cutting strategy are illustrated in Fig. 6. The depicted mean value and standard

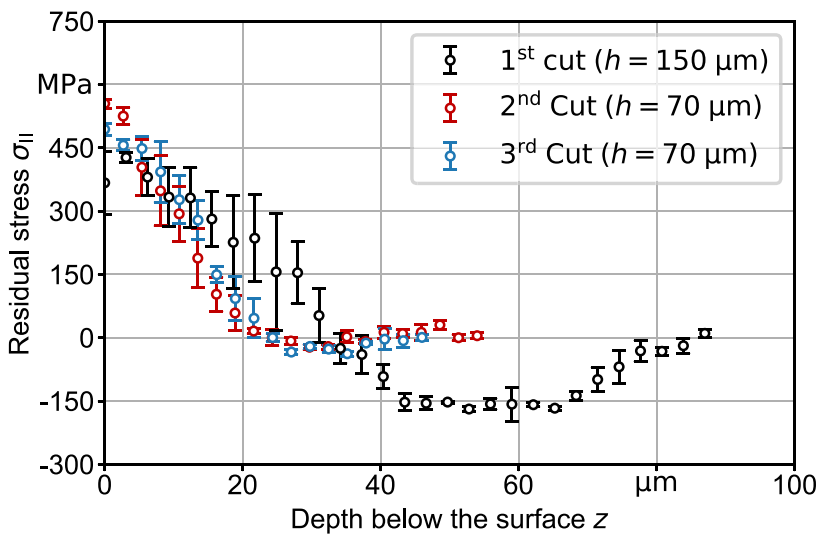

Fig. 6 Depth profiles of residual stress measured in cutting direction indicating the mean value and corresponding standard deviation for each experimental point. The initial cut was conducted with an undeformed chip thickness of $h=150 \mu \mathrm{m}$ 
deviation for each experimental point were calculated from the results of four single measurements. After the initial cut with an undeformed chip thickness of $h=150 \mu \mathrm{m}$, tensile residual stresses of up to $\sigma_{\text {II }} \approx 400 \mathrm{MPa}$ were generated at the surface. At a depth of $z \approx 34 \mu \mathrm{m}$, a compressive stress state was present. The maximum compressive stress value of $\sigma_{\text {II }}=-169 \mathrm{MPa}$ was reached at a depth of $z \approx 53 \mu \mathrm{m}$. The compressive stress diminished significantly at a depth of $z \approx 68 \mu \mathrm{m}$ and converged to zero at $z \approx 87 \mu \mathrm{m}$ resulting in a thickness of the compressive layer of approx. $56 \mu \mathrm{m}$. This characteristic profile consisting of tensile residual stresses at the surface, which change to compressive stresses with increasing depth, is reported in literature for orthogonal cutting of quenched and tempered steel [20]. In the experiments, the compressive layer was almost entirely removed in the subsequent cut, due to the undeformed chip thickness of $h=70 \mu \mathrm{m}$. The residual stress profile resulting from the second cut displayed slightly higher tensile stresses at the workpiece surface. Hence, an influence of the undeformed chip thickness on the heat generation at the workpiece surface, which is strongly effected by friction [14], is not apparent. The transition into compressive stress occurred at a lower depth of $z \approx 24 \mu \mathrm{m}$ compared to the stress profile generated by the initial cut. The maximum value of compressive stress was significantly smaller and amounted to $\sigma_{\mathrm{II}}=-23 \mathrm{MPa}$ at a depth of $z \approx 30 \mu \mathrm{m}$. Since the depth profiles of the stress resulting from the second and the third cut resemble each other closely, the influence of the first cut appears to be limited to the second cut, which is in accordance with the results of the force measurements, see Fig. 5. Therefore, the machining of the altered workpiece material layer generated by the initial cut led to a decrease of the process forces in the subsequent cut.

Additionally, a higher chip thickness of $h=210 \mu \mathrm{m}$ in the initial cut resulted in a stress formation with similar tensile

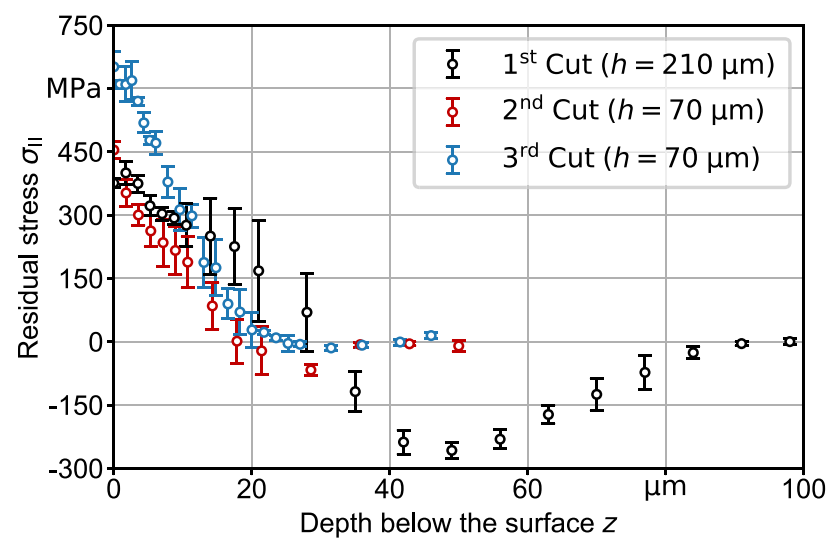

Fig. 7 Depth profiles of residual stress measured in cutting direction indicating the mean value and corresponding standard deviation for each experimental point. The initial cut was conducted with an undeformed chip thickness of $h=210 \mu \mathrm{m}$ stresses and significantly higher compressive stress values of up to $\sigma_{\text {II }}=-257.5 \mathrm{MPa}$ compared to a cut with a thickness of $h=150 \mu \mathrm{m}$, see Fig. 7. This can be explained primarily by an increase of the process forces, which led to higher compressive mechanical loads acting on the workpiece [14]. The depth profile measured after the second cut subsequent to a cut with $h=210 \mu \mathrm{m}$ was similar to the measurements of the subsequent cuts depicted in Fig. 6 whereas the tensile stress measured in the third cut appeared to be an outlier. In general, higher uncertainties of the XRD measurements could be observed in the presence of large stress gradients, as is particularly the case for the tensile stress layer. Since the machining of the stress layer generated by the initial cut with $h=210 \mu \mathrm{m}$ led to a stronger decrease of the process forces in the subsequent cut, the residual stress formation, particularly the compressive layer, may have contributed significantly to this effect. In this regard, a microstructural characterization of the subsurface area resulting after the described cutting processes was conducted to examine the occurrence of microstructural alterations due to plastic deformation, possibly influencing subsequent cuts.

\subsection{Microstructural characterization of the subsurface}

In order to characterize the microstructure of the subsurface, SE micrographs of a cross-sectional area of the cut sample $(h=210 \mu \mathrm{m})$ used in the residual stress measurements (see Fig. 7) are depicted in Fig. 8. Due to the heat treatment described in Sect. 2.1, a homogeneous microstructure of relaxed martensite was formed (Fig. 8a). An alteration of

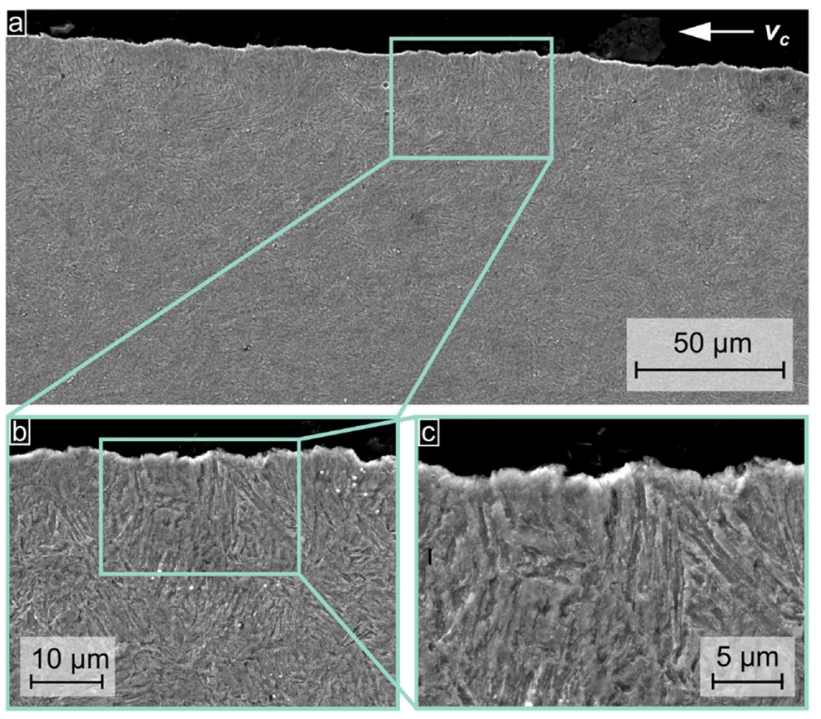

Fig. 8 SE micrograph of the cross section of a machined sample $(h=210 \mu \mathrm{m})$ parallel to the cutting direction at different magnification levels $(\mathbf{a}-\mathbf{c})$ 


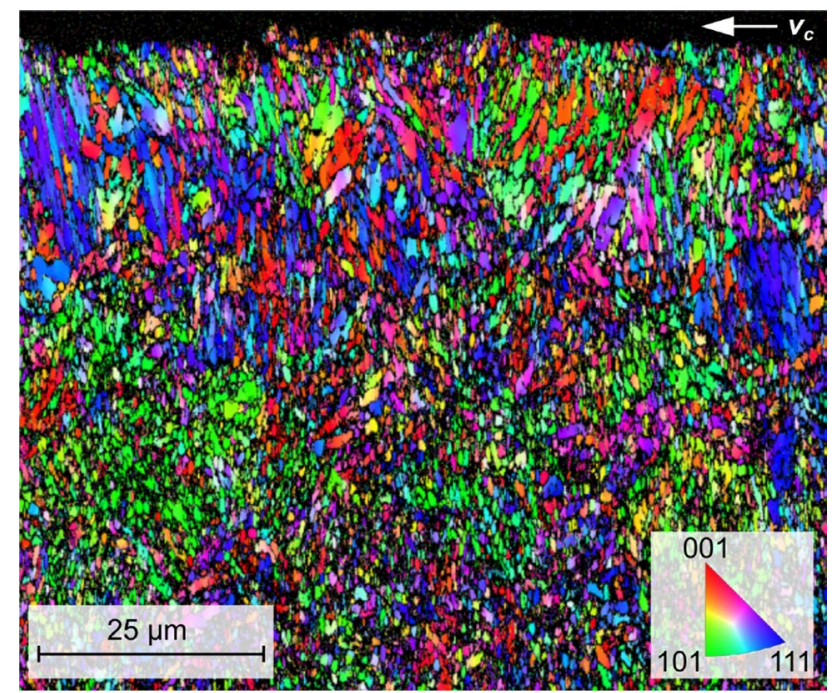

Fig. 9 IPF map of the cross section of a machined sample $(h=210 \mu \mathrm{m})$ parallel to the cutting direction

the microstructure of the material close to the cut surface is not visible, as there was, e.g., no detectable alignment of grains in shearing direction parallel to the surface due to the cutting motion, which would indicate severe material deformation [21].

Additionally, EBSD measurements were conducted to generate inverse pole figure (IPF) maps, which provide information on the orientation, size and distribution of grains. On this basis, the subsurface can be investigated with regard to the occurrence of effects such as plastic deformation or grain refinement due to the cutting process [10]. An IPF map of the cross-sectional area of the sample $(h=210 \mu \mathrm{m})$ is depicted in Fig. 9. The IPF map displays a number of longer grains up to a depth of about $z=30 \mu \mathrm{m}$. Some of these grains are orientated normal to the cut surface. Below this area, the microstructure consisted of smaller grains. These local differences could be a result of prior forming processes and the conducted heat treatment. Substantial plastic deformations due to the cut such as elongated and distorted grains oriented in shearing direction were not apparent. Only a refinement of grains at the surface down to a depth of $z \approx 5 \mu \mathrm{m}$ could be observed. With the exception of grain refinement at the surface, a significant alteration of the microstructure in the subsurface due to the cutting process could not be observed for the conducted cutting processes with $h=70 \mu \mathrm{m}, 150 \mu \mathrm{m}$ and $210 \mu \mathrm{m}$ by means of SEM and EBSD measurements.

As an additional characterization technique, nanoindenter tests were conducted to investigate the occurrence of process-related alterations by evaluating the hardness of the microstructure. In this context, the normalized hardness of the machined workpiece shown in Fig. 9 and a sample cut with $h=70 \mu \mathrm{m}$ is depicted in Fig. 10 as a function of depth from the cut surface. The measurements were performed

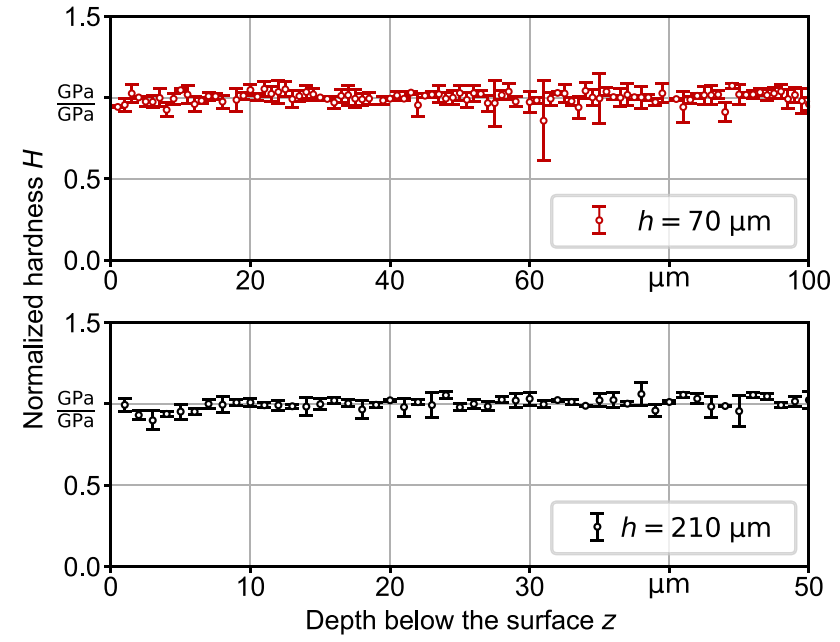

Fig. 10 Normalized, averaged hardness and corresponding standard deviation as a function of depth from the cut surface

up to a depth of $z=100 \mu \mathrm{m}$ and $50 \mu \mathrm{m}$ below the machined surface. For the sample machined with an undeformed chip thickness of $h=70 \mu \mathrm{m}$, no significant variation of the measured hardness was apparent towards the cut surface. An influence of the residual stresses present in the subsurface in the form of tensile stress and minor compressive stress (see second cut in Fig. 7) on the measured hardness is not evident. Likewise, the hardness measurements of the sample machined with an undeformed chip thickness of $h=210 \mu \mathrm{m}$ display no systematic deviations as a function of the depth. An effect of the measured compressive stresses of up to $\sigma_{\text {II }}=-257.5 \mathrm{MPa}$ at a depth of $z=49 \mu \mathrm{m}$ (see first cut in Fig. 7) cannot be identified. The results of the nanoindentations are consistent with the observations made on the basis of SE micrographs and IPF maps. According to these, no significant, profound microstructural alterations or strain hardening, which can be correlated to an increased hardness in the subsurface [22], occurred due to the cutting process. Therefore, process-related residual stress formations apparently contribute significantly to the decrease of process forces in subsequent cuts.

Regarding the nanoindentation tests, the effects of residual stress on the measurements are described as small, rarely leading to a variation of hardness of more than $10 \%$ in case of an uniaxial loaded specimen [23]. Accordingly, tensile stress is likely to lead to a decrease in hardness and compressive stress to an increase. A variation of this scale could not be identified from the measured hardness depicted in Fig. 10 considering the present standard deviation of the measurements. 


\section{Numerical model of consecutive orthogonal cuts}

Based on the presented results, a consideration of material history for the evaluation of process forces is beneficial. In this context, the application of FE simulations can be useful for a specific analysis of this effect. FE models have been widely applied to determine residual stress in machining operations [24]. In literature, however, only few studies can be found, which explicitly addressed the formation of residual stresses generated by consecutive cuts [25-27] or its effect on the process forces of consecutive cuts [28, 29]. The influence of initial stress on the cutting forces was also investigated using a numerical simulation [30]. In this work, the orthogonal cutting process was simulated using the commercial FE software Abaqus/Explicit and the Coupled Eulerian-Lagrangian (CEL) method as a modelling approach. The workpiece model was described by an Eulerian and the tool by a Langrangian formulation using coupled temperature-displacement elements. An advantage of this approach is the unrestricted movement of material through the Eulerian domain as a result of contact with the tool [31]. Therefore, effects like mesh distortions due to increasing material deformation, which can be critical for modelling the chip formation process, can be avoided. The use of techniques such as remeshing [32, 33] and element deletion [34], necessary to cope with the resulting numerical inaccuracies, are not required. The CEL method was applied in recent times to model orthogonal metal cutting [35,36], which is characterized by large strains as well as high strain rates and temperatures. Its applicability has been demonstrated by a comparison with other commonly used modeling approaches such as the Arbitrary Eulerian-Lagrangian (ALE) formulation using different commercial software for FE analysis [37]. Furthermore, the CEL method was adopted to model machining processes such as single grain cutting [38] and friction experiments [39]. An evaluation of the basic ability of the model to analyze the effect of material history by

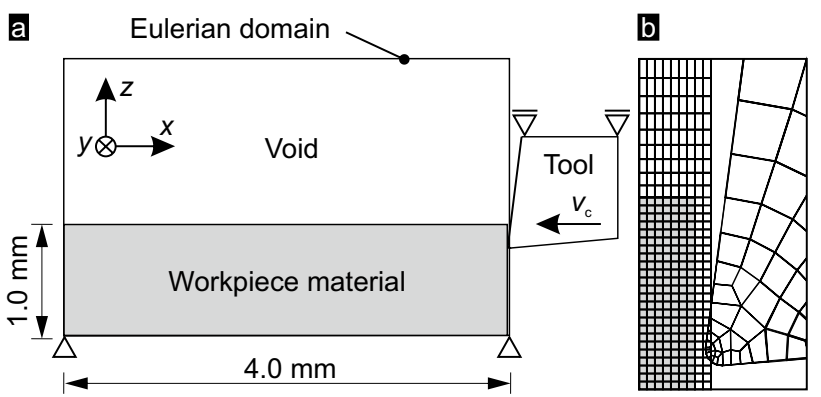

Fig. 11 FE model (a) and its initial mesh (b). The cutting motion was carried out by the tool, the workpiece was fixed reproducing process-related residual stresses and their effect on the process forces is subject of this section.

The model consisted of 3D elements of the type EC3D8RT with one element in lateral $y$-direction with a width of $20 \mu \mathrm{m}$. The area below the workpiece surface was meshed with elements of the size of $10 \mu \mathrm{m}$ down to a depth of $h+200 \mu \mathrm{m}$ in $z$-direction, depending on the defined undeformed chip thickness $h$. The area above the workpiece surface was meshed with elements of gradually increasing length from $15 \mu \mathrm{m}$ up to $100 \mu \mathrm{m}$ (see Fig. 11).

Its height depended on the defined undeformed chip thickness. Therefore, the amount of elements and the resulting computing time could be reduced while preserving a sufficient modeling of the chip formation process, which is essential for the formation of residual stress in the subsurface. As a result, a maximum number of 32160 elements were generated. In order to ensure plane strain cutting conditions, the displacement in lateral direction of the nodes in the Eulerian domain was constrained. Both, the workpiece and the tool, were initially assigned the ambient temperature of $293.15 \mathrm{~K}$.

A constant sink temperature of $293.15 \mathrm{~K}$ was defined on the surfaces of the tool opposite the flank and rake face as well as on the bottom side of the workpiece to represent the conduction of heat in the workpiece and the tool during cutting. The constitutive law by Johnson and Cook (JC), which can be used to describe metal machining operations with high strain rates [8], was applied to model the material response during the cutting process. The yield stress was determined as

$\sigma_{\mathrm{y}}=\left(A+B \varepsilon_{\mathrm{p}}^{n}\right)\left(1+C \log \frac{\dot{\varepsilon}_{\mathrm{p}}}{\dot{\varepsilon}_{0}}\right)\left(1-\left\langle\frac{T-T_{0}}{T_{\mathrm{m}}-T_{0}}\right\rangle^{m}\right)$

with the temperature $T$, the equivalent plastic strain $\epsilon_{\mathrm{p}}$, the equivalent plastic strain rate $\dot{\epsilon}_{\mathrm{p}}$, a reference temperature $T_{0}$ and the melting temperature $T_{\mathrm{m}}$ of the workpiece material. The parameter $A, B$ and $n$ were determined by conducting tensile tests with a defined reference strain rate $\dot{\epsilon}_{0}$. The parameter $C$ and $m$ were identified by performing experiments using a Split Hopkinson Pressure Bar (SHPB) setup [40] at different strain rates and temperatures. All parameter values were determined using common methods of regressive analysis (i.e. bounded BFGS optimization schemes) [41].

To account for the elastic behavior of the HSS tool, which has a significantly lower Young's modulus compared to, e. g., cemented carbide, it was modeled as an elastic body and meshed with 101 elements of the type C3D8RT. The parameter values used for the numerical simulation are listed in Tables 2 and 3. The contact between the tool and the workpiece was modeled using the Coulomb friction law with a velocity-dependent coefficient, calculated as 
Table 2 Material properties of HSS (AISI M2) [43] and AISI 4140 used for the numerical simulations

\begin{tabular}{lll}
\hline Young's modulus $(E)$ & AISI 4140 & $231.752 \mathrm{GPa}$ \\
& HSS & $210 \mathrm{GPa}$ \\
Poisson's ratio $(v)$ & AISI 4140 & 0.3 \\
& HSS & 0.3 \\
Density $(\rho)$ & AISI 4140 & See Table 3 \\
& HSS & $8150 \mathrm{kgm}^{-3}$ \\
Specific heat $\left(c_{\mathrm{p}}\right)$ & AISI 4140 & See Table 3 \\
& HSS & $550 \mathrm{~J} /(\mathrm{kgK})$ \\
Conductivity $(\lambda)$ & AISI 4140 & See Table 3 \\
& HSS & $21.3 \mathrm{~W} /(\mathrm{mK})$ \\
Expansion $(\alpha)$ & AISI 4140 & $13 \times 10^{-6} \mathrm{~K}^{-1}$ \\
& HSS & $11.9 \times 10^{-6} \mathrm{~K}^{-1}$ \\
JC model parameter & $A$ & $1010.439 \mathrm{MPa}$ \\
(AISI 4140) & $B$ & $510.898 \mathrm{MPa}$ \\
& $n$ & 0.1490 \\
& $C$ & 0.0155 \\
& $m$ & 1.4629 \\
& $\dot{\varepsilon}_{0}$ & $0.00033 \mathrm{~s}^{-1}$ \\
& $T_{\mathrm{m}}$ & $1793.15 \mathrm{~K}$ \\
& $T_{0}$ & $298.15 \mathrm{~K}$ \\
\hline
\end{tabular}

Table 3 Measured density, specific heat and conductivity values of AISI 4140 as a function of the temperature

\begin{tabular}{llll}
\hline $\begin{array}{l}\text { Temperature } \\
\mathrm{K}\end{array}$ & $\begin{array}{l}\text { Density } \\
\mathrm{kg} \mathrm{m}^{-3}\end{array}$ & $\begin{array}{l}\text { Specific heat } \\
\mathrm{J} /(\mathrm{kgK})\end{array}$ & $\begin{array}{l}\text { Conductivity } \\
\mathrm{W} /(\mathrm{mK})\end{array}$ \\
\hline 293.15 & 7832.8 & 460 & 38.6 \\
373.15 & 7799.4 & 475 & 38.4 \\
473.15 & 7764.9 & 495 & 36.9 \\
573.15 & 7736.2 & 545 & 36.4 \\
673.15 & 7702.5 & 615 & 36.6 \\
773.15 & 7669.1 & 705 & 36.1 \\
873.15 & 7636.5 & 800 & 33.8 \\
973.15 & 7605.3 & 970 & 31.9 \\
1073.15 & 7629.5 & 765 & 30.3 \\
1173.15 & 7582.4 & 730 & 30.5 \\
1273.15 & 7541.0 & 800 & 34.3 \\
\hline
\end{tabular}

$\mu\left(v_{\mathrm{s}}\right)=2.1646 \cdot v_{\mathrm{s}}^{-0.42}$

with $v_{\mathrm{s}}$ in $\mathrm{m} / \mathrm{min}^{-1}$. The coefficients were determined from friction experiments using a modular cutting system [15], which followed an approach presented by Puls et al. [39] and showed a significant velocity dependency. The inelastic heat fraction, which specifies the amount of plastic work converted to heat, was set to $\eta=0.9$. A thermal conductance between the tool and the workpiece was applied in the presence of contact pressure using a coefficient of $\alpha_{\mathrm{t}, \mathrm{wp}}=1000 \mathrm{~kW} /\left(\mathrm{m}^{2} \mathrm{~K}\right)[42]$.

In order to evaluate the basic ability of the FE model to simulate the effect of the material history, two exemplary process strategies were simulated including an orthogonal cut with an undeformed chip thickness of $h=70 \mu \mathrm{m}$ (reference cut) as well as two consecutive cuts. Since larger undeformed chip thicknesses in the first cut led to an enhanced decrease of the process forces in the subsequent cut, a first cut with $h=210 \mu \mathrm{m}$ followed by a cut with $70 \mu \mathrm{m}$ was conducted as the application scenario. A stress relaxation step including a heat transfer between the workpiece and the ambient air by convection using an coefficient of $\alpha_{\mathrm{c}}=20 \mathrm{~kW} /\left(\mathrm{m}^{2} \mathrm{~K}\right)$ [44] was performed between the two cuts. Prior to this step, the tool was disengaged from the workpiece to eliminate the influence of tool contact on the stress state [24]. According to the experiments conducted, the cutting velocity was set to $v_{\mathrm{c}}=60 \mathrm{~m} \mathrm{~min}^{-1}$. The shape of the cutting edge corresponded to the tool used in the experiments (see Table 1).

Six paths were defined equidistantly within a $1 \mathrm{~mm}$ wide interval depicted in Fig. 12a in order to extract the principal stress at the integration points in cutting direction. The interval had a distance of $0.75 \mathrm{~mm}$ from the chip root to ensure a more stationary stress gradient and a representative result. The simulated stress distribution of the machined workpiece

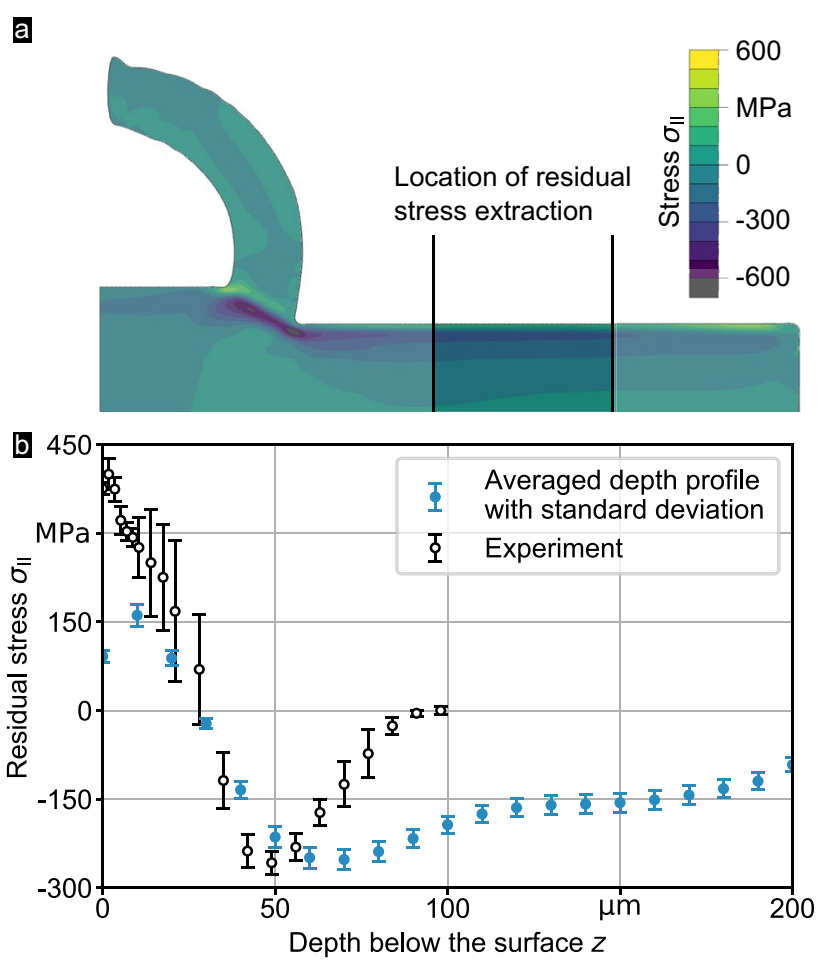

Fig. 12 Location of residual stress extraction (a) and the corresponding simulated and experimental depth profile generated by a cut with an undeformed chip thickness of $h=210 \mu \mathrm{m}$ (b) 
and the extracted depth profiles generated by an orthogonal cut with $h=210 \mu \mathrm{m}$ are depicted in Fig. 12. Similar to the corresponding experiment, tensile stress was present in the material near the surface. The maximum averaged value of $\sigma_{\mathrm{II}}=161.3 \mathrm{MPa}$ was smaller by approx. $\sigma_{\mathrm{II}}=239 \mathrm{MPa}$ compared to the measurement. The decrease of the simulated tensile stress value at the machined surface was due to the spatial resolution of the workpiece model in the Eulerian domain. Accordingly, elements along the cut surface consisted not entirely of material and, therefore, leading to reduced stress values. The tensile stresses transitioned into a compressive state between a depth of $20 \mu \mathrm{m}<z<30 \mu \mathrm{m}$. The maximum compressive stress value of $\sigma_{\mathrm{II}}=-252 \mathrm{MPa}$ was reached at a depth of $z=70 \mu \mathrm{m}$, which resembled the measured value of $\sigma_{\text {II }}=-257.5 \mathrm{MPa}$ at a depth of $z=49 \mu \mathrm{m}$ closely. The calculated compressive layer was propagated in higher depths compared to the measured stress profile. A decrease of the compressive stresses towards the bulk material was not as distinct as in the measurement leading to the presence of compressive stresses in depths $z>100 \mu \mathrm{m}$. Nonetheless, the FE model provided comparable conditions since the material machined by the consecutive cut displayed a tensile and compressive layer as in the experiments. In particular, the maximum compressive residual stress value was reproduced accurately, while the tensile residual stresses near the surface were underestimated. A comparison between the computed process force components $F_{\mathrm{c}}^{\prime}$ and $F_{\mathrm{n}}^{\prime}$ in cutting and normal direction (parallel to the $x$ - and $z$-direction, respectively) of the consecutive, second cut $(h=70 \mu \mathrm{m})$ and an equivalent
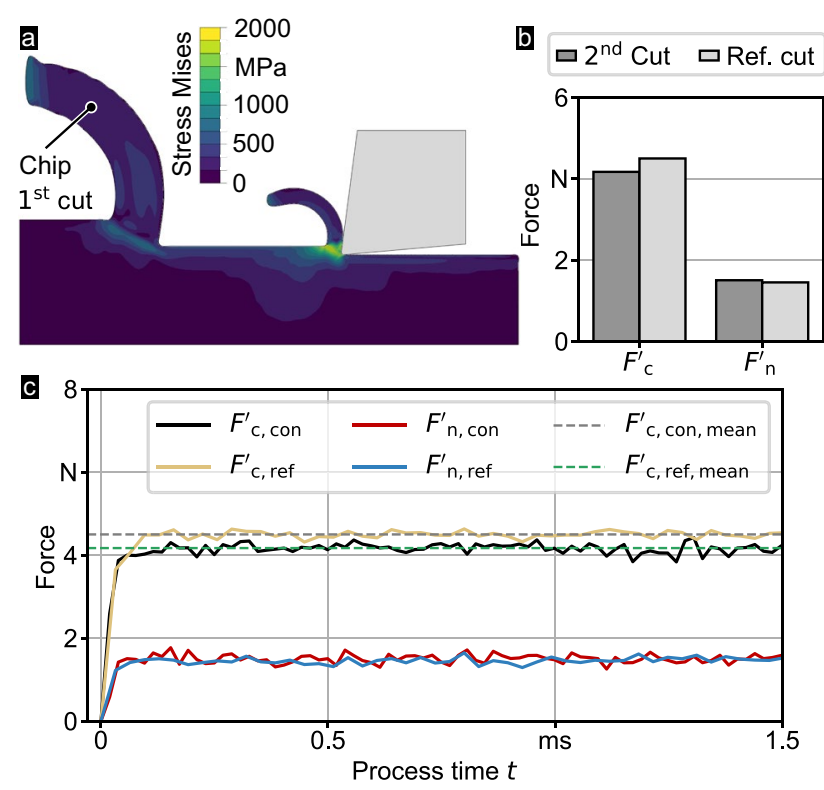

Fig. 13 Simulation of the consecutive cut (a), the resulting average forces for a consecutive cut $(h=70 \mu \mathrm{m})$ and an equivalent reference cut with no preexisting stress state (b), based on the respective calculated process forces (c) reference process with no preexisting stress state present are depicted in Fig. 13b. The cutting force in the reference cut $\left(F_{\mathrm{c}, \text { ref }}^{\prime}=4.5 \mathrm{~N}\right)$ was about $8 \%$ higher than in the consecutive cut $\left(F_{\mathrm{c}, \mathrm{con}}^{\prime}=4.17 \mathrm{~N}\right)$, in which a decrease due to process-related alterations such as residual stress occurred. This decrease was significantly smaller than observed in the experiments (see Fig. 5). A reduction of the forces in normal direction did not occur, but rather a slight increase, which is not in accordance with the experimental results. A comparison of the experimental and simulated process forces in general shows deviations, especially in the normal force, which, in addition to the parameterization of the models, can for that matter also be attributed to a nonlinear correlation of the process forces on such different scales.

A sufficiently accurate prediction of force variations due to the effect of material history and process-related residual stresses as an important subsurface characteristic could not be achieved. A reason for this may be the absence of a material damage model, which could have a significant effect on subsurface alterations and, therefore, on the calculated forces in subsequent cuts. Furthermore, detailed investigations are required to analyze the influence of, e. g., different undeformed chip thicknesses and cutting velocities on the simulated residual stress formation taking, for instance, the residual stress perpendicular to the cutting direction into account.

\section{Conclusion and outlook}

Orthogonal cutting strategies were conducted in AISI 4140 to analyze the influence of preceding cuts and their undeformed chip thickness on subsequent cuts. Therefore, the process forces and the residual stress depth profile of the corresponding samples were measured. The presented results indicate a significant influence of subsurface alterations generated by preceding orthogonal cutting operations causing a decrease of the process forces in the subsequent cut. In this regard, an increase of the chip thickness resulted in larger compressive stress values and layers as well as enhanced decreases of the process forces in subsequent cuts. In order to analyze a potential influence of microstructural subsurface alterations due to process-related plastic deformations on this effect, SE micrographs and EBSD measurements werde conducted. The resulting SEM pictures and IPF maps showed no indications of severe plastic deformation due to the cut such as elongated or distorted grains, except for a layer of $z \approx 5 \mu \mathrm{m}$ at the surface consisting of refined grains. Nanoindentations of the cut samples quantifying the hardness of the material exhibited no systematic increase towards the cut surface due to strain hardening effects. Based on these results, a significant contribution of process-related residual stress as an important subsurface characteristic on the decrease of process forces can be derived. 
Therefore, considering the history of the cut material can be beneficial for the evaluation of process forces. The development of a corresponding force model based on the results presented will be a subject of future work. In this regard, the use of a numerical simulation modeling process-related residual stress and the decrease of process forces due to subsurface alterations is essential. Thus, a numerical model was set up using the CEL method as a modeling approach. The workpiece material was characterized by conducting tensile tests and SHPB experiments in order to parameterize the material model. In addition, the temperature dependency of essential material properties was determined. The calculated maximum compressive stress value of the model presented was similar to the measurement conducted after a cut with an undeformed chip thickness of $h=210 \mu \mathrm{m}$. As seen in the experiments, tensile stresses were present near the surface, which transitioned into a compressive stress layer. The model tends to underestimate tensile stresses and overestimate the depth of the compressive layer compared to the measurements. A process-related decrease of the forces in the process subsequent to a cut with $h=210 \mu \mathrm{m}$ occurred only in cutting direction on a smaller scale than in the experiments. Further investigations are necessary to develop a model suitable for analyzing the effect of material history and to understand the mechanical correlation to this effect.

Acknowledgements The investigations are based on the research project "Virtual Machining" (PE-216-0024), which is kindly funded by the Stiftung Mercator and the Mercator Research Center Ruhr. The authors would like to thank the Center for Interface-Dominated High Performance Materials (ZGH) at the Ruhr University Bochum for the use of the CLSM.

Funding Open Access funding enabled and organized by Projekt DEAL.

Open Access This article is licensed under a Creative Commons Attribution 4.0 International License, which permits use, sharing, adaptation, distribution and reproduction in any medium or format, as long as you give appropriate credit to the original author(s) and the source, provide a link to the Creative Commons licence, and indicate if changes were made. The images or other third party material in this article are included in the article's Creative Commons licence, unless indicated otherwise in a credit line to the material. If material is not included in the article's Creative Commons licence and your intended use is not permitted by statutory regulation or exceeds the permitted use, you will need to obtain permission directly from the copyright holder. To view a copy of this licence, visit http://creativecommons.org/licenses/by/4.0/.

\section{References}

1. Altintas Y, Yellowley I (1989) In-process detection of tool failure in milling using cutting force models. Adv Manuf 63:149-157. https://doi.org/10.1115/1.3188744

2. Tlusty J (1978) Analysis of the state of research in cutting dynamics. CIRP Ann 27(2):583-589
3. Altintas Y, Kersting P, Biermann D, Budak E, Denkena B, Lazoglu I (2014) Virtual process systems for part machining operations. CIRP Ann 111(2):585-605. https://doi.org/10.1016/j.cirp. 2014.05.007

4. Kienzle O (1952) Die Bestimmung von Kräften und Leistungen an spanenden Werkzeugen und Werkzeugmaschinen. VDI-Z 94(11-12):299-305

5. Budak E, Altintas Y, Armarego E (1996) Prediction of milling force coefficients from orthogonal cutting data. J Manuf Sci Eng 118:216-224. https://doi.org/10.1115/1.2831014

6. Oxley PLB, Shaw MC (1990) Mechanics of machining: an analytical approach to assessing machinability. J Appl Mech 57(1):253

7. Özel T, Zeren E (2004) Determination of work material flow stress and friction for fea of machining using orthogonal cutting tests. $J$ Mater Process Technol 153:1019-1025

8. Melkote SN, Grzesik W, Outeiro J, Rech J, Schulze V, Attia H, Arrazola P-J, M'Saoubi R, Saldana C (2017) Advances in material and friction data for modelling of metal machining. CIRP Ann 66(2):731-754. https://doi.org/10.1016/j.cirp.2017.05.002

9. Bergmann JA, Kimm J, Theisen W, Wiederkehr P (2020) An approach to use sub-surface characteristics for the prediction of process forces during cutting operations. Procedia CIRP 88:276281. https://doi.org/10.1016/j.procir.2020.05.048

10. Jawahir IS, Brinksmeier E, M'Saoubi R, Aspinwall DK, Outeiro JC, Meyer D, Umbrello D, Jayal AD (2019) Surface integrity in material removal processes: recent advances. CIRP Ann 60(2):603-626. https://doi.org/10.1016/j.cirp.2011.05.002

11. Guo YB, Warren AW, Hashimoto F (2010) The basic relationships between residual stress, white layer, and fatigue life of hard turned and ground surfaces in rolling contact. CIRP J Manufact Sci Technol 2(2):129-134. https://doi.org/10.1016/j.cirpj.2009. 12.002

12. Outeiro JC, Umbrello D, M'Saoubi R (2006) Experimental and numerical modelling of the residual stresses induced in orthogonal cutting of AISI 316L steel. Int J Mach Tools Manuf 46:17861794. https://doi.org/10.1016/j.ijmachtools.2005.11.013

13. Dehmani H, Salvatore F, Hamdi H (2013a) Numerical study of residual stress induced by multi-steps orthogonal cutting. Procedia CIRP 8:299-304. https://doi.org/10.1016/j.procir.2013.06.106

14. M'Saoubi R, Outeiro JC, Changeux B, Lebrun JL, Morao Dias A (1999) Residual stress analysis in orthogonal machining of standard and resulfurized AISI 316L steels. J Mater Process Technol 96:225-233. https://doi.org/10.1016/S0924-0136(99)00359-3

15. Wöste F, Baumann J, Bergmann JA, Garcia Carballo R, Wiederkehr P (2020) Experimental setup for analyzing fundamentals of cutting processes using a modular system. MM Sci J March:3754-3758. https://doi.org/10.17973/MMSJ.2020_03_ 2020004

16. Delbergue D, Texier D, Lévesque M, Bocher P (2016) Comparison of two X-ray residual stress measurement methods: Sin2 and $\cos$, through the determination of a martensitic steel $\mathrm{x}$-ray elastic constant. In: Residual stresses 2016: ICRS-10, vol 2, pp 55-60. https://doi.org/10.21741/9781945291173-10

17. Li X, Bhushan B (2002) A review of nanoindentation continuous stiffness measurement technique and its applications. Mater Char 48(1):11-36. https://doi.org/10.1016/S1044-5803(02)00192-4

18. Oliver WC, Pharr GM (1992) An improved technique for determining hardness and elastic modulus using load and displacement sensing indentation experiments. J Mater Res 7(6):1564-1583. https://doi.org/10.1557/JMR.1992.1564

19. Baumann J, Krebs E, Biermann D (2019) Chatter avoidance in milling by using advanced cutting tools with structured functional surfaces. MM Sci J 1:3019-3026. https://doi.org/10.17973/MMSJ. 2019_11_2019045 
20. Jacobus K, DeVor RE, Kapoor SG (2000) Machining-induced residual stress: experimentation and modeling. J Manuf Sci Eng 122(1):20-31

21. Kimm J, Pöhl F, Wiederkehr P, Theisen W (2020) Subsurface microstructure evolution and residual stress in $42 \mathrm{crmo} 4$ steel after single-pass pendulum tests. Int J Mech Eng Robot Res 9:10721080. https://doi.org/10.18178/ijmerr.9.8.1072-1080

22. Warren AW, Guo YB, Weaver ML (2006) The influence of machining induced residual stress and phase transformation on the measurement of subsurface mechanical behavior using nanoindentation. Surf Coat Technol 200(11):3459-3467. https://doi.org/ 10.1016/j.surfcoat.2004.12.028

23. Tsui TY, Oliver WC, Pharr GM (1996) Influences of stress on the measurement of mechanical properties using nanoindentation: Part i. experimental studies in an aluminum alloy. J Mater Res 11(3):752-759. https://doi.org/10.1557/JMR.1996.0091

24. Sadeghifar M, Sedaghati R, Jomaa W, Songmene V (2018) A comprehensive review of finite element modeling of orthogonal machining process: chip formation and surface integrity predictions. Int J Adv Manuf Technol 96:3747-3791. https://doi.org/10. 1007/s00170-018-1759-6

25. Guo YB, Liu CR (2002) Fem analysis of mechanical state on sequentially machined surfaces. Mach Sci Technol 6(1):21-41. https://doi.org/10.1081/MST-120003183

26. Dehmani H, Salvatore F, Hamdi H (2013b) Numerical study of residual stress induced by multi-steps orthogonal cutting. Procedia CIRP 8:299-304. 14th CIRP Conference on Modeling of Machining Operations (CIRP CMMO). https://doi.org/10.1016/j.procir. 2013.06.106

27. Nasr M (2015) Effects of sequential cuts on residual stresses when orthogonal cutting steel aisi 1045. Procedia CIRP 31:118-123. In: 15th CIRP conference on modelling of machining operations (15th CMMO). https://doi.org/10.1016/j.procir.2015.03.032

28. Liu CR, Guo YB (2000) Finite element analysis of the effect of sequential cuts and tool-chip friction on residual stresses in a machined layer. Int J Mech Sci 42(6):1069-1086. https://doi.org/ 10.1016/S0020-7403(99)00042-9

29. Tounsi N, El-Wardany T (2015) Finite element analysis of chip formation and residual stresses induced by sequential cutting in side milling with microns to sub-micron uncut chip thickness and finite cutting edge radius. Adv Manuf 3:309-322. https://doi.org/ 10.1007/s40436-015-0128-Z

30. Ma Y, Yu DW, Feng PF (2014) Fem analysis of residual stress distribution and cutting forces in orthogonal cutting with different initial stresses. In: High speed machining VI, volume 800 of materials science forum, pages 380-384. Trans Tech Publications Ltd, 8 2014. https://doi.org/10.4028/www.scientific.net/MSF.800801.380

31. Skrzat A (2012) Application of coupled eulerian-lagrangian approach in metal forming simulations. Zeszyty Naukowe Politechniki Rzeszowskiej. Mechanika, (84 [284], nr 4):25-35. https://doi.org/10.7862/rm.2012.9

32. Baeker M, Rösler J, Siemers C (2002) A finite element model of high speed metal cutting with adiabatic shearing. Comput Struct 80(5):495-513. https://doi.org/10.1016/S0045-7949(02)00023-8
33. Schulze V, Zanger F (2011) Development of a simulation model to investigate tool wear in ti-6al-4v alloy machining 223:535-544. https://doi.org/10.4028/www.scientific.net/AMR.223.535

34. Ceretti E, Fallböhmer P, Wu WT, Altan T (1996) Application of $2 \mathrm{~d}$ fem to chip formation in orthogonal cutting. J Mater Process Technol 59(1):169-180. https://doi.org/10.1016/0924-0136(96) 02296-0

35. Zhang Y, Outeiro JC, Mabrouki T (2015) On the selection of johnson-cook constitutive model parameters for ti-6al-4v using three types of numerical models of orthogonal cutting. Procedia CIRP 31: 112-117. In: 15th CIRP conference on modelling of machining operations (15th CMMO). https://doi.org/10.1016/j. procir.2015.03.052

36. Ducobu F, Rivière-Lorphèvre E, Filippi E (2016) Application of the coupled eulerian-lagrangian (cel) method to the modeling of orthogonal cutting. Eur J Mech A Solids 59:58-66. https://doi. org/10.1016/j.euromechsol.2016.03.008

37. Ducobu F, Arrazola PJ, Rivière-Lorphèvre E, Ortiz de Zarate G, Madariaga A, Filippi E (2017) The cel method as an alternative to the current modelling approaches for ti6al4v orthogonal cutting simulation. Procedia CIRP 58:245-250. In: 16th CIRP conference on modelling of machining operations (16th CIRP CMMO). https://doi.org/10.1016/j.procir.2017.03.188

38. Wöste F, Siebrecht T, Fast M, Wiederkehr P (2019) Geometric physically-based and numerical simulation of nc-grinding processes for the calculation of process forces. Procedia CIRP 86:133-138. https://doi.org/10.1016/j.procir.2020.01.022

39. Puls H, Klocke F, Lung D (2014) Experimental investigation on friction under metal cutting conditions. Wear 310(1):63-71. https://doi.org/10.1016/j.wear.2013.12.020

40. Al-Mousawi MM, Reid SR, Deans WF (1997) The use of the split hopkinson pressure bar techniques in high strain rate materials testing. Proc Inst Mech Eng Part C J Mech Eng Sci 211(4):273292. https://doi.org/10.1243/0954406971522042

41. Zhu C, Byrd RH, Lu P, Nocedal J (1995) L-bfgs-b—fortran subroutines for large scale bound constrained optimization. In: Technol Report Department of Electrical Engineering and Computer Science. Northwestern University, Evanston

42. Filice L, Umbrello D, Micari F, and Settineri L (2007) On the finite element simulation of thermal phenomena in machining processes. Springer, Berlin, pp 263-278. https://doi.org/10.1007/3540-69845-0_16

43. Davis JR (2001) Properties and selection: irons, steels and highperformance alloys, volume 1 of ASM handbook. ASM International, Materials Park, Ohio, [10. ed.], 6. print edition. ISBN 978-0871703774

44. Tiffe $M$ (2018) Charakterisierung grundlegender Mechanismen für die Simulation der Spanbildung mithilfe der FEM. PhD thesis, TU Dortmund University

Publisher's Note Springer Nature remains neutral with regard to jurisdictional claims in published maps and institutional affiliations. 